\title{
The influence of knowledge and sociodemographics on AIDS perception and sexual practices among secondary school students in Nigeria
}

\author{
*Oyeyemi $\mathrm{YA}^{1}$, Abdulkarim A², Oyeyemi $\mathrm{BO}^{3}$
}

1. Hunter College Graduate Center, City University of New York, New York, NY 10016 USA, and Susan Smith McKinney Nursing \& Rehabilitation Center, 594 Albany Avenue, Brooklyn, NY 11203, USA.

2. Department of Paediatrics, University of Ilorin Teaching Hospital, Ilorin, Nigeria.

3. Department of Pediatrics, Federal Medical Center, Katsina, Nigeria.

\begin{abstract}
Background: Recent trends show a disproportionate increase in new incidences of HIV infection among teenagers compared to other population segments.

Objectives: This study assessed secondary school students' perception of AIDS epidemic, and the influence of sociodemographic variables and AIDS knowledge on their perception and sexual practices.

Methods: Nigerian teenagers ( $N=1143$ ) were surveyed using a questionnaire that elicited information on their demographics, AIDS knowledge, perceptions and previous encounter with survivors, and sexual practices.

Results: Although AIDS epidemic was not a serious issue of concern to a substantial number of the students, they were knowledgeable on AIDS, and their perceptions on AIDS epidemics influenced their sexual practices. Female teenagers were more knowledgeable and concerned, and more frequently reported inexperience with sexual intercourse compared to their male counterparts.

Conclusion: AIDS education and campaigns that foster the internalization of the seriousness of AIDS epidemics and arouse concern about them could enhance safe sexual practices among the youths.
\end{abstract}

Keywords: AIDS epidemics, Sexual Behavior, Condom Use, Perception

African Health Sciences 2011; 11(S1): S67 - S76

\section{Introduction}

Adequate knowledge is crucial to clearing misconceptions about sexually transmitted diseases (STD) including acquired immune deficiency syndrome (AIDS), and in promoting healthy sexual behavior among adolescents and young adults. Teenage school children are subject to the influence of family members, health experts and teachers, may have explorative attitudes, and may be exposed to peer pressure in their sexual behavior. Current global trends show a disproportionate increase in new incidences of human immunodeficiency virus (HIV) infection among 15-24 year olds, compared to other population segments in many countries including Nigeria ${ }^{1}$. Understanding the sexual behavior of this segment of the population is crucial for success in

\begin{tabular}{l}
\hline *Correspondence author \\
Dr. Adetoyeje Y Oyeyemi \\
Dr. Susan Smith McKinney Nursing \& \\
Rehabilitation Center \\
594 Albany Avenue, Brooklyn \\
NY 11203 \\
Telephone (718) 2707216 \\
E-mail: oyeyemia@nychhc.org \\
\hline
\end{tabular}

African Health Sciences Vol 11 Special Issue 1 August 2011 the effort to curtail the spread of HIV and AIDS in Africa.

Previous studies found discrepancy in teenagers and young adults' knowledge about AIDS, and safe sexual practices ${ }^{2-6}$. Young adults are sexually active, have high AIDS awareness ${ }^{4-5}$, but seldom use contraceptives on a consistent basis ${ }^{2,3,7}$, making them vulnerable to STD and AIDS $^{8}$. Young female adults have shown preference for abstinence over condom use, than their male counterparts 9 . Factors that could influence African adolescents' sexual behavior and contraceptive decisions are prevailing gender norms, attitude towards procreation, and fear of HIV infection. It has been hypothesized that young adults' decision on whether or not to have sex may be influenced by a shared value on the importance of parenthood, and a decision to use condoms may be viewed as a negation of parenthood ${ }^{10}$. Other possible factors could include how serious they perceive the problem of AIDS epidemics, and how concerned they are about the problem. It is plausible that the results of campaigns to improve AIDS knowledge and awareness as well as sexual practices 
among youths in Nigeria may be limited if such campaigns did not influence them sufficiently to appreciate the seriousness of the AIDS epidemic and heighten their feeling of concern about the epidemics.

Under the 6-3-3-4 educational system in Nigeria, students spend six years in the elementary school, three years in the junior secondary school, three years in senior secondary schools, and four years for the university education. Anecdotal reports show that teenagers in secondary schools receive sexual health education, the content of which varies from school to school and state to state. The effect of this sexual health education on the students' AIDS awareness and their perception about AIDS epidemics is unclear. The age of $15-17$ is critical in life because this is the time that a debut is made into sexual maturity and teenagers are prone to exploring their sexuality. As part of their development, any foundation on morals that has been formed in early years may be tested and new values explored in teenage years.

Available studies of young adults' sexual behavior in Africa were focused on those within the diverse age range of 15-24 in Tanzania, Nigeria, Ghana and Ethiopia ${ }^{4,5,7,9}$. Presently, there is a paucity of data on Nigerian youths between the ages of 1517, and only one African study was found that surveyed children within the school setting, presumed to be free of adult relatives' potentially intrusive presence $^{11}$. No firm data exist on African adolescents' perception of seriousness of AIDS epidemics, how concerned they are about the epidemics, where teenagers in Nigeria get information about AIDS, and on their perceived resource needs on AIDS.

Based on evidence, a curriculum based approach that includes activities consistent with community values, involving local personnel of diverse backgrounds and cognizant of the relevant need of the youth, is an effective means of influencing youths' sexual behavior, and has been recommended ${ }^{12}$. Information on young adults' perception on AIDS contributes to our awareness about this population as it relates to sexually transmitted diseases and AIDS, and is therefore important for planning, design and packaging of any intervention directed at the teenage population in Nigeria. In this country of over 140 million people, 3.3 million are infected with HIV at an average prevalence rate of $3.6 \%$ (UNAIDS 2008).

The purpose of this study was to (1) assess teenage secondary school students' perception of
AIDS epidemic, their information sources and needs and (2) to determine the influence of sociodemographic variables and AIDS knowledge on the students' perception of AIDS epidemic and their sexual behavior.

\section{Methods}

\section{Sample}

The sample consisted of students in four public secondary schools in the city of Ilorin, Nigeria. The schools were randomly selected from an ordered listing based on the socioeconomic status of the resident population. The listing was a consensus by five selected officials of the state ministry of education each with over 25 years of teaching and secondary school administration experience in the city. Students' permissions were obtained verbally and their parents' written consents were obtained through a cover letter distributed a few days prior to the scheduled date of questionnaire administration. Students whose parents objected were excused from participation. No name or any identification was required and anonymity was assured. Questionnaires were administered within a two-week period in May 2008, after a class session and with the cooperation of the school officials. The sample consisted of 1,143 students in their second or third year in the senior secondary school.

\section{Research Questionnaire}

We adapted a 52-item questionnaire consisting of two parts, from a similar survey of American adolescents and young adults ${ }^{14}$. Adaptation made was to rephrase the wording to conform to English usage in Nigeria. Part I consisted of eight questions that solicited sociodemographic information including sex and age. Participants were asked how serious they thought the problem of AIDS epidemics was and how concerned they were about the epidemics. The responses were "Very Serious", "Very Concerned", "Serious" or "Concerned", "A Little Serious" or "A Little Concerned" and "Not at all serious" or "Not at all concerned". Subjects were also asked whether they knew someone who tested positive, or had died of AIDS.

Part II consisted of four subscales of 44 items that evaluated respondents knowledge about AIDS, where they obtain information about AIDS, in what aspects of AIDS would they like to have more information, AIDS testing, and sexual behavior and practices. Subscale 1 evaluated students knowledge about AIDS and consisted of 13 
questions on the pattern, transmission, prognosis and testing. The questions were framed to elicit "True", "False" or "Don't Know" responses. Only the correct answers were counted and 'not sure' responses were not given any credit. The minimum and maximum possible score were zero and 13 respectively. A score of nine and above indicated a satisfactory knowledge and awareness about AIDS.

Subscale 2 consisted of 10 questions designed to assess where the respondents obtain information about AIDS. The students rated their responses as "A lot", "A little" or "None" to the listed sources. Subscale 3 solicited information on the aspects of AIDS that the respondents would like to have more information, and on AIDS testing, and consisted of 16 questions. Possible responses were "Yes" and "No" for the first 11 questions. The remaining four questions of this subscale asked those who had been tested and why they were tested. The options were "I was asked to be tested", "the doctor told me", or "under the impression that it was a routine part of an examination". Those who had not been tested were asked why they have not been tested. Available choices are "Have not done anything that puts you at risk", "Afraid your parents would find out", and "Afraid you will test positive". The respondents rated the reason as "major reason", "minor reason", or "not a reason".

Subscale 4 pertained to their sexual behavior and consisted of 5 questions on kissing, touching and fondling in a sexual manner, and sexual intercourse experience. Possible responses were "Yes" or "No" to the first four questions. The last question elicited information on condom use from those who reported they had experience with sexual intercourse. The possible responses were "All of the time", "Most of the time", "Only some of the time" and "None of the time"

Two physician specialists, one in the areas of adolescent medicine and the other on STD and AIDS, reviewed the questionnaire to ascertain the face validity of the knowledge subscale. Two schoolteachers and a guidance counselor attested to the appropriateness and language of the questionnaire for the Nigerian teenage population. The physician experts agreed to the face validity of the knowledge subscale and the teachers and counselor agreed as to the appropriateness of the questionnaire contents to the targeted population. In order to determine the reliability of our measuring instrument, the questionnaire was administered to 20 secondary school students on two occasions with a retest interval of two weeks. The Pearson productmoment correlation coefficients obtained for the knowledge, information source and needs, AIDS testing, sexual health and behavior subscales of the questionnaire were $0.93,0.84,0.82$ and 0.87 respectively, indicating moderate to high reproducibility.

\section{Procedure}

Prior to administering the questionnaires, the school principals were notified and their permission was obtained. Students in their second and third years in the senior secondary school who returned the signed consent from their parents participated in the study. On the day the questionnaires were administered, the aim of the study was explained to the students and their cooperation was solicited. Participants were informed that they were free to leave anytime if they were no longer interested in participating in the survey. The questionnaires were administered after classes between $13.00-14.00$ hours local time. A time limit was not imposed, the but majority of the students completed the questionnaires within 25 minutes. One thousand two hundred and fifty four questionnaires were distributed and 1,151 were returned, out of which 1,143 were usable, giving a response rate of $91.1 \%$.

\section{Data Analysis}

For each of the completed questionnaires, we recorded the responses for all subscales, and for subscale 2, we also determined the number of correct responses. Data was analyzed using AnalyzeIt statistical software (Analyze-It Software, Leeds, UK). Means and frequencies were computed for all variables. Parametric analysis of variance (ANOVA) was utilized to explore differences in knowledge, and nonparametric ANOVA and Chi square tests were used to explore perceptions and sexual practices. Significant main effects were probed with schiffe post hoc test because of the unequal sample sizes of the subgroups and Tukey's test was utilized where applicable. Statistical significant level was fixed at 0.05. Multiple and stepwise regression models were used to determine the contributions of some dependent variables toward previous experience with sexual intercourse and condom use (criteria variables), at the tolerance level of $0.01(\mathrm{~F}>4.00)$. Subjects were also dichotomized into satisfactory (knowledge score of 9.0 or better) and unsatisfactory (scores less than 
9.0) groups to assess any differences based on knowledge and awareness level on AIDS.

\section{Results}

The mean age of the respondents was $16.8(\mathrm{SD}=2.1)$ and the mean score on knowledge was $9.8(\mathrm{SD}=2.7)$. As Table 1 shows, $54.6 \%$ of the respondents were males, while $45.5 \%$ were females. Most of the students $(80.0 \%)$ believed AIDS epidemic is either a very serious or a serious issue, while $68.3 \%$ were either very concerned or were concerned about the epidemic. Majority (66.8\%) did not know any person diagnosed with AIDS and $76.9 \%$ did not know any person who tested positive.

Table 1: Students' demographic characteristic, personal encounters and perception on AIDS epidemics $(\mathrm{N}=1143)$

\begin{tabular}{lll}
\hline Variables & $\mathbf{n}$ & $\mathbf{\%}$ \\
\hline Gender: & & \\
$\quad$ Male & 624 & 54.6 \\
$\quad$ Female & 519 & 45.4 \\
How Serious: & & \\
$\quad$ Very serious & 780 & 68.2 \\
Serious & 135 & 11.8 \\
A little serious & 91 & 8.0 \\
Not serious & 137 & 12.0 \\
How Concerned: & & \\
$\quad$ Very concerned & 639 & 55.9 \\
$\quad$ Concerned & 142 & 12.4 \\
\hline
\end{tabular}

Continutaion of table 1

\begin{tabular}{|c|c|c|}
\hline Variables & $\mathrm{n}$ & $\%$ \\
\hline \multicolumn{2}{|c|}{ A Little Concerned 84} & 7.3 \\
\hline Not concerned & 278 & 24.4 \\
\hline \multicolumn{3}{|c|}{ Know Persons with AIDS: } \\
\hline Yes & 224 & 19.9 \\
\hline No & 899 & 80.1 \\
\hline \multicolumn{3}{|c|}{ Know person diagnosed with AIDS: } \\
\hline Yes & 379 & 33.2 \\
\hline No & 764 & 66.8 \\
\hline \multicolumn{3}{|c|}{ Know person who tested positive: } \\
\hline Yes & 264 & 23.1 \\
\hline No & 879 & 76.9 \\
\hline
\end{tabular}

Respondents' sources of information on AIDS and gender pattern of responses are shown in table 2 . Many $(71.8 \%)$ of the respondents obtained a lot of information on AIDS from television or movies. Many students $(54.5 \%)$ obtained a lot of this information from their parents, while $64.6 \%$ obtained a lot from physicians. The medium through which the students got AIDS information the least is the internet $(39.0 \%)$. Forty-one percent of the teenagers got a lot of information from their siblings and their nurses. Female students tend to frequently report getting information from their parents $(\mathrm{Chi}$ statistics $=14.9)$ and siblings $($ Chi statistics $=10.6)$ more than their male counterparts $(p<0.01)$.

Table 2: Students' sources of information on AIDS and proportional differences by gender

\begin{tabular}{|c|c|c|c|c|c|c|c|}
\hline \multirow[t]{2}{*}{ Variable } & \multicolumn{2}{|l|}{ A lot } & \multicolumn{2}{|c|}{ A Little } & \multicolumn{2}{|c|}{ None } & \multirow[t]{2}{*}{ Chi Value } \\
\hline & $\mathrm{n}$ & $\%$ & $\mathrm{n}$ & $\%$ & $\mathrm{n}$ & $\%$ & \\
\hline Friends & 518 & 45.3 & 366 & 25.6 & 259 & 22.7 & 4.39 \\
\hline Parents & 623 & 54.5 & 262 & 22.9 & 258 & 22.6 & $14.89 *$ \\
\hline Brothers and sisters & s 469 & 41.0 & 341 & 29.8 & 333 & 29.1 & $10.55^{*}$ \\
\hline Teachers & 567 & 49.6 & 323 & 28.3 & 253 & 22.1 & 4.52 \\
\hline School Nurse & 469 & 41.0 & 266 & 23.3 & 408 & 35.7 & 2.56 \\
\hline Physician & 739 & 64.6 & 203 & 17.8 & 201 & 17.6 & 0.23 \\
\hline Television/movies & 821 & 71.8 & 201 & 17.6 & 121 & 10.6 & 5.49 \\
\hline Brochures/pamphle & lets 715 & 62.6 & 253 & 22.1 & 175 & 15.3 & $32.13^{*}$ \\
\hline Magazines/N.Paper & rs 725 & 63.4 & 289 & 25.3 & 129 & 11.3 & $12.21 *$ \\
\hline Internet & 446 & 39.0 & 278 & 24.3 & 419 & 36.7 & 2.50 \\
\hline
\end{tabular}

* Indicates values with significant proportional differences $(\mathrm{p}<0.01)$ in responses by gender. The females tend to report parents, brothers and sisters, brochure/pamphlets and magazines/newspapers as sources of their information more frequently than their male counterparts.

N. Papers $=$ Newspapers 
In Table 3, we see students' information needs and differences in gender proportions. An overwhelming majority of the students indicated the need for information on how to protect themselves from AIDS (89.2\%), and how to talk to their parents $(75.5 \%)$ and partners $(79.3 \%)$ about AIDS. The majority $(61.2 \%)$ needed information on the proper ways to use condoms, while those who believed schools should provide them with condom were in the minority (36.5\%), and $32.7 \%$ reported experience with sexual intercourse. Majority have experienced kissing $(52.2 \%)$, while those who have ever been french kissed, or have been involved in touching and fondling a partner in a sexual manner were in the minority (34.3\% and $37.0 \%$ respectively). Male students tend to report experience with sexual intercourse and having been kissed, french kissed, or touched and fondled by the opposite sex in a sexual manner, than their female counterparts (Chi square $>32.0, \mathrm{p}<0.01)$.

Table 3: Students' need, sexual practices, and proportional differences by gender $(\mathrm{N}=1143)$

\begin{tabular}{|c|c|c|c|c|c|}
\hline Variable & Yes & & No & & Chi statistics \\
\hline Need information on: & $\mathrm{n}$ & $\%$ & $\mathrm{n}$ & $\%$ & \\
\hline What is AIDS & 999 & 87.4 & 144 & 12.6 & 0.32 \\
\hline How is AIDS spread & 1006 & 88.0 & 137 & 12.0 & 0.46 \\
\hline How to talk with your parents AA & 863 & 75.5 & 280 & 24.5 & $8.13^{*}$ \\
\hline How to talk with a partner AA & 906 & 79.3 & 237 & 20.7 & 0.80 \\
\hline How to protect self & 1020 & 89.2 & 123 & 10.8 & 0.26 \\
\hline Where to go to get tested & 848 & 74.2 & 295 & 25.8 & 0.12 \\
\hline Proper way to use condoms & 699 & 61.2 & 444 & 39.8 & 0.00 \\
\hline Available drugs for treatment & 828 & 72.4 & 315 & 27.6 & 0.31 \\
\hline Should school provide condoms & & 417 & 36.5 & 726 & $63.5 \quad 0.37$ \\
\hline Ever been tested & 188 & 16.4 & 955 & 83.6 & $4.94 * *$ \\
\hline Ever been kissed & 597 & 52.2 & 546 & 47.8 & $39.11 *$ \\
\hline Ever been french kissed & 392 & 34.3 & 751 & 65.7 & $32.42 *$ \\
\hline Ever involved in touching and fondling & 423 & 37.0 & 720 & 67.0 & $71.19^{*}$ \\
\hline Ever had sexual intercourse & 374 & 32.7 & 769 & 67.3 & $54.53^{*}$ \\
\hline
\end{tabular}

* Indicates values with significant proportional differences $(\mathrm{p}<0.01)$ in responses by gender.

** Indicates values with significant proportional differences $(\mathrm{p}<0.05)$ in responses by gender

$\mathrm{AA}=$ About AIDS

In all the cases where there are differences, the females tend to report having ever been tested, kissed, french kissed, touched and fondled, experienced with sexual intercourse, and needs information on how to talk to parents more than their male counterparts.

The students' responses on testing and use of condom as shown in table 4 . Of the few $(n=188)$ who have been tested, $42.6 \%$ were tested at a general (public) health clinic. Some (37.8\%) of those who

were tested knew because a physician or nurse told them. Of those who were not tested, 56.4\% considered not having done anything that put them at risk as a major reason, while $63.9 \%$ considered this not a reason. Almost $20 \%$ of the students did not consider being afraid their parents would find out as a reason for not being tested. Male students tend to report condom use more frequently than their female counterparts (Chi statistics $=22.1$, $\mathrm{P}<0.01)$.

Table 4: Subjects' responses on AIDS testing, condom use and proportional differences by gender

\begin{tabular}{llll}
\hline Variable & $\mathbf{n}$ & $\mathbf{\%}$ & Chi Statistics \\
\hline Where did you go to get tested & & & \\
HIV clinic & 66 & 35.1 & \\
General health clinic & 80 & 42.6 & 6.32 \\
Private doctors' office & 42 & 22.3 & \\
Part of blood drive & 0 & 0.0 & \\
\hline
\end{tabular}




\begin{tabular}{cccc}
\hline Variable & $\mathbf{n}$ & $\mathbf{\%}$ & Chi Statistics \\
\hline How did you know you were tested & & & \\
I was asked to be tested & 56 & 29.8 & \\
Doctor/nurse told me & 71 & 37.8 & 1.25 \\
Routine exam impression & 61 & 32.4 & \\
Reason you have not been tested & & & \\
Not done anything that puts you at risk & & & \\
Major reason & 561 & 56.4 & \\
Minor reason & 118 & 12.3 & 2.20 \\
Not a reason & 276 & 28.9 & \\
Afraid parents will find out & & & \\
Major reason & 187 & 19.6 & \\
Minor reason & 158 & 16.5 & 0.10 \\
Not a reason & 610 & 63.9 & \\
Afraid you will test positive & & & \\
Major reason & 212 & 22.2 & \\
Minor reason & 139 & 14.6 & 0.27 \\
Not a reason & 604 & 63.2 & \\
$\quad$ & & &
\end{tabular}

Those who perceived AIDS epidemics as a very serious issue scored significantly higher $(\mathrm{p}<0.01)$ on knowledge than others who perceived it as less serious (Table 5). Similarly, those who were very concerned about the epidemic scored significantly $(\mathrm{p}<0.01)$ higher on knowledge than those who were not concerned at all. The female students scored significantly $(\mathrm{p}<0.05)$ better overall on knowledge than their male counterparts, while those who had previous experience with sexual intercourse scored less than those who did not. No significant difference in knowledge score was observed by response on condom use. When subjects were dichotomized into satisfactory (knowledge scores of 9.0 or above) and unsatisfactory (scores less than 9.0) groups, those whose scores were unsatisfactory tend to be older (mean $=17.1 \mathrm{SD}=2.2$ ) than those whose scores were satisfactory (mean $=16.7 \mathrm{SD}=2.0$ ).

Table 5: Differences in students' knowledge differences by gender, level of perceived seriousness and concern about AIDS epidemics and sexual behavior

\begin{tabular}{lll}
\hline Variables & \multicolumn{1}{c}{ Mean (SD) } & \multicolumn{1}{c}{ P-value } \\
\hline Gender & & \\
Male & $9.2(2.4)^{\mathrm{a}}$ & \\
Female $\quad 9.7(2.4)^{\mathrm{b}}$ & 0.0003 \\
Ever had sexual intercourse & \\
Yes $\quad 9.2(2.5)^{\mathrm{a}}$ & 0.0216 \\
No & $9.5(2.4)^{\mathrm{b}}$ & \\
\hline S72 & &
\end{tabular}

Continuation of table 5

\begin{tabular}{|c|c|c|}
\hline Variables & Mean (SD) & P-value \\
\hline \multicolumn{3}{|l|}{ Condom use } \\
\hline All of the time & $8.9(2.6)$ & \multirow{4}{*}{0.0610 (NS) } \\
\hline Most of the time & $8.6(2.7)$ & \\
\hline Some of the time & e $9.1(2.1)$ & \\
\hline None of the time & e $9.4(2.5)$ & \\
\hline \multicolumn{3}{|c|}{ How serious } \\
\hline Vey serious & $9.7(2.3)^{\mathrm{a}}$ & \multirow{4}{*}{0.0040} \\
\hline Serious & $9.0(2.6)^{b}$ & \\
\hline A little serious & $9.0(2.3)^{\mathrm{b}}$ & \\
\hline Not at all serious & $9.0(2.5)^{\mathrm{b}}$ & \\
\hline \multicolumn{3}{|c|}{ How concerned } \\
\hline Very concerned & $9.6(3.9)^{\mathrm{a}}$ & \multirow{4}{*}{0.0001} \\
\hline Concerned & $9.1(2.4)$ & \\
\hline A little concerned & $9.5(2.2)$ & \\
\hline \multicolumn{2}{|c|}{ Not at all concerned $8.7(2.9)^{\mathrm{b}}$} & \\
\hline \multicolumn{3}{|c|}{ Ever has sexual intercourse } \\
\hline Yes & $9.2(2.5)^{\mathrm{a}}$ & \\
\hline No & $9.5(2.4)^{b}$ & 0.0216 \\
\hline \multicolumn{3}{|c|}{ Ever been French kissed } \\
\hline Yes & $9.1(2.6)^{\mathrm{a}}$ & \\
\hline No & $9.6(2.3)^{b}$ & 0.0021 \\
\hline \multicolumn{3}{|c|}{ Ever touch and fondled opposite sex } \\
\hline Yes & $9.1(2.6)^{\mathrm{a}}$ & \\
\hline No & $9.6(2.3)^{\mathrm{b}}$ & 0.0002 \\
\hline \multicolumn{3}{|l|}{ Ever been kissed } \\
\hline Yes & $9.3(2.5)^{\text {a }}$ & \\
\hline No & $9.5(2.4)^{b}$ & 0.0870 (NS) \\
\hline
\end{tabular}


Means with different superscripts are significantly different from each other. Means without superscripts are not significantly different from those with superscripts.

Those who were very concerned about AIDS epidemics for people of their age tended to be younger $(p<0.01)$ than those who were not so concerned or not concerned at all $(16.7 \mathrm{SD}=1.9$ vs. 17.7 SD=2.1). Those who did not perceive AIDS epidemics as a serious issue (Chi statistics $=20.6)$ and those who did not feel it is an issue of concern to people of their age (Chi statistics $=15.3)$ tend to report experience with sexual intercourse than those who perceive it as serious and of concern to people of their age. Students who knew any person who tested positive with HIV tended to report condom use more frequently $($ Chi statistics $=11.8, \mathrm{P}<0.01)$ than their counterparts who did not know any such person.

Data was also analyzed to determine the influence of demographic factors on sexual practices. Female respondents were more concerned about AIDS epidemics than their male counterparts were $(p<0.01)$. Those who felt the AIDS epidemic was a serious issue or were concerned about it tend to report experience with sexual intercourse less frequently than their counterparts who did not $(p<0.001)$. When condom use consistency was dichotomized into "some of the time" and "none of the time" on one hand, and "all of the time" and "most of the time" on the other hand, those who perceived the AIDS epidemic as a serious issue and those who were concerned about it tend to use condom "all the time" or "most of the time" compared to their counterparts who did not feel the epidemics is a serious issue or of concern to people of their age. This result showed the positive influence of AIDS perception on sexual practices.

Further analysis was conducted to determine the combined and relative contributions of some selected variables (age, gender, knowledge and the AIDS related perception) towards the prediction of sexual experience and condom use. Multiple regression analysis revealed that age $\left(R^{2}=0.062\right)$, gender $\left(\mathrm{R}^{2}=0.131\right.$, perception of seriousness $\left(\mathrm{R}^{2}=0.020\right)$ and concern $\left(\mathrm{R}^{2}=0.022\right)$ about the AIDS epidemic, contributed statistically significantly to the prediction of sexual experience $(\mathrm{F}=15.6, \mathrm{p}<0.01)$. Age, gender, knowledge and perception of seriousness predicted condom use of any consistency at the coefficient of determination $\left(\mathrm{R}^{2}\right)$ of 0.032 , $0.051,0.013$ and 0.016 respectively $(\mathrm{F}=13.3, \mathrm{P}<0.01)$.
These variables combined accounted for $23.5 \%$ and $11.2 \%$ of the variance in sexual experience and condom use respectively, indicating their importance in the youths' sexual behavior.

\section{Discussion}

Most (80.0\%) of the teens perceived the AIDS epidemic as serious and the majority $(68.3 \%)$ viewed it as an issue of concern to people of their age. This response is similar to those of the 15-17 year old US teenagers, $89 \%$ and $53 \%$ of whom reported it was a serious issue and of concern to them respectively ${ }^{14}$. The discrepancy in the proportion of students who perceived AIDS as a serious issue and those who were concerned about it may be explained by a hypothesis postulated by Brown ${ }^{3}$. According to this hypothesis, adolescents and young adults tend to acknowledge risk of HIV and STD, while simultaneously minimizing their vulnerability to these diseases.

Television or movies, and magazines or newspapers were the students' main sources of information on AIDS. This finding is similar to those of Bradner et $\mathrm{al}^{15}$, in which $87.0 \%$ of young American male adults aged between 22 and 26 reported television, and $74.6 \%$ reported magazines, as the most common source of information about AIDS. A greater proportion of the Nigerian students in this study obtained a lot of information from physicians than the young Americans (64.6\% vs. $18.4 \%$ ) in Bradner et al's study. This latter finding should be viewed on a positive note because health professionals are presumed to be more credible source of AIDS information compared to the lay media. Furthermore, as previous studies showed, those who obtain information from physicians and other health experts are more likely to discuss contraceptives with their partners than those who obtained such information from other sources ${ }^{14,16}$.

Except for kissing, sexual activities was restricted to less than half of the students, and an overwhelming majority $(67.3 \%)$ had not had experience with sexual intercourse or even engaged in touching and fondling the opposite sex in a sexual manner $(67.0 \%)$. This finding contrasts with the behavior of the elementary and high school students in Tanzania, an overwhelming majority of whom reported experience with sexual intercourse at the age of 14-15 years ${ }^{11}$. The level of sexual activity among teenagers in the present study is also below those of the Ethiopian out-of-school youths with an average age of 19 years, $46.3 \%$ of whom 
reported experience with sexual intercourse, and that of Nigerian and Ugandan university students ${ }^{4,5}$. It is however similar to those of Ghanaian adolescents and young adults 33\% (40.2\% male and 26.0\% female) of whom reported a history of sexual intercourse $e^{7}$. The lower level of sexual activity found in the present study may be attributed to the lower age of the adolescents in this study compared to those of the other African youths in the previous studies.

The influence of perception on sexual practices found in this study showed that education and AIDS awareness campaigns may be more effective if they convey the seriousness of AIDS epidemics to young adults. This finding suggests that techniques that demonstrate AIDS fatalities and provide appropriate disclosures are important to curtail the spread of AIDS among the youths. Our finding that those with no previous experience with sexual intercourse scored higher on knowledge than those with history of sexual intercourse suggests a positive influence of knowledge on abstinence, and is in agreement with a previous report that AIDS education delays sexual experience among high school students in the Philippines ${ }^{17}$. This study also suggests that knowledge is influential to the students' perception of seriousness of AIDS epidemic, and their feeling of concern about the epidemic, and not engaging or delaying the onset of benign sexual activities such as French kissing, and touching and fondling the opposite sex partner.

Our finding that the females were more knowledgeable about AIDS, were more concerned, and did not report experience with sexual intercourse compared to their male counterparts suggests that healthy behavior is more common among secondary school females than their male counterparts. Female teenagers' report of lack of sexual intercourse history indirectly points at their abstinence corroborated by a previous study9. The finding also supports earlier reports that male adolescents are more likely to initiate sexual activity earlier than their female counterparts $^{18}$. A prevalence of condom use among the male students compared to their female counterpart is similar to the pattern found among Ghanaian, Ethiopian and Kenyan youths ${ }^{7,9,19}$ and American adolescents ${ }^{18-19}$. This pattern of condoms use may be attributed to the relative ease of procurement and application of male condom alluded to by a previous study ${ }^{8}$. A plausible explanation could also be that in African society, the males are less inhibited in expressing their sexuality and may therefore feel less shy to request for or buy condoms and admit to using them, compared to their female counterparts.

\section{Limitation of the Study}

A general belief is that data on sensitive behaviors such as sexual activities and condom use could be problematic. Consequently, a rampant skepticism about the quality of survey data on premarital sexual activity $^{20,21}$, has been blamed on interview methods utilized in eliciting responses ${ }^{19}$. Although audio computer-assisted self-interviewing has been favored as a method of choice in collecting data on sensitive behavior elsewhere ${ }^{22-25}$, the relative efficacy of the self interviewing method over the paper and pencil questionnaire system as used in the present study has not been substantiated for any sub-Saharan population group. This may be due to the paucity of ownership and access to computers in the region.

Adolescents and young adults in the present study may have underreported their experience with sexual intercourse and their engagement in benign sexual activities such as kissing, touching and fondling the opposite sex partner. The students may not be fully confident that their response will not be tracked in the school setting even though anonymity was assured. Possible underreporting by the male students may be counterweighted by cultural factors believed to be consistent with young men exaggerating (and young women denying) their sexual activity because of differences in sexuality expression ${ }^{20}$. Furthermore, as with any self-reported survey, participants may have provided responses they felt were acceptable to the researchers. Overall, the above limitations may not pose any substantial problem to the generalizability of the findings of this study.

\section{Conclusion}

Although young adults in this study are knowledgeable on AIDS, some of the students did not regard the AIDS epidemic as a serious societal issue and it did not arouse the concern of many of the students. While sexual activity among the students is mostly limited to benign sexual activities, a substantial number of these teenagers have begun to experience sexual intercourse by their penultimate or final years in secondary school, and many of these sexually active teenagers do not use condoms on a consistent basis. The study identified gender and age as modest predictors of sexual experience and condom use. It affirms that knowledge contributes 
to abstinence among teenage students and suggests that education and campaigns that heighten the students' appreciation of the seriousness of AIDS epidemics and arouse their concern about the epidemics could serve to improve the effectiveness of an intervention. Techniques that enhance the internalization of the seriousness of AIDS epidemics and arouse feeling of concern, such as reporting of AIDS related deaths, and appearances of public figures and celebrities during AIDS education and campaigns should receive emphasis in packaging AIDS education and campaigns directed at the youths.

\section{References}

1. UNAIDS. Children and AIDS: Third Stock Taking Reports 2008. Geneva 2009. Available at http://www.data.unaids.org/pub/reports/ 2008. Accessed March 25, 2011.

2. Hingson R, Strunin L, and Berlin B. Acquired Immunodeficiency Syndrome Transmission:Changes in Knowledge and Behaviors among Teenagers, Massachusetts Statewide Surveys, 1986 to 1988. Pediatrics 1990; 25(1):24-29

3. Brown EJ, AIDS-related risk behavior of young college students. Association of Black Faculty Nurse Journal 2000;11(2):3743

4. Sekirime WK, Tamale J, Lule JC, WabwireMangen F. Knowledge, attitude and practice about sexually transmitted diseases among university students in Kampala. African Health Science. 2000; (1):16-22

5. Arowojolu AO, Ilesanmi AO, Roberts OA, Okunola MM. Sexuality, contraceptive choice and AIDS awareness among Nigerian undergraduates. African journal of Reproductive Health 2002; 6(2):60-70

6. James S, Reddy SP, Taylor M, Jinabhai CC. Young people, HIV/AIDS/STIs and sexuality in South Africa: the gap between awareness and behavior. Acta Paediatrica 2004; 93(2):2649

7. Agyei WK, Biritwum RB, Ashitey AG, Hill RB. Sexual behavior and contraception among unmarried adolescents and young adults in greater Accra and Eastern regions of Ghana. Journal of Biosocial Science 2000; 32(4):495-512

8. Mahoney CA, Thombs DL, Ford OJ. Health beliefs and self efficacy models: their utility in explaining college students' condom use. AIDS Education and Prevention 1995; 7(1):32-9
9. Taffa N, Klepp KI, Sundby J, Bjune G. Psychosocial determinants of sexual activity and condom use intention among youth in Addis Ababa, Ethiopia. International Journal of STD and AIDS 2002;13(10):714-9

10. Smith DJ. Premarital Sex, Procreation, and HIV Risk in Nigeria. Studies in Family Planning 2004;35(4): 223-235

11. Matasha E, Ntembelea T, Mayaud P, Saidi W, Todd J, Mujaya B et al. Sexual and reproductive health among primary and secondary school pupils in Mwanza, Tanzania: need for intervention. AIDS Care 1998; 10(5):571-82.

12. Kirby D, Obasi A, Laris BA. The effectiveness of sex education and HIV education interventions in schools in developing countries. World Health Organization Technical Report Service 2004; 934:103-50/317-341

13. UNAIDS HIV and AIDS Estimates 2009. Available at http://www.unaids.org/en/ regionscountries/countries/nigeria. Accessed Marc 25, 2011

14. Kaiser Family Foundation (KFF). National Survey of Adolescents and Young Adults; Sexual Health Knowledge, Attitudes and Experiences. www.kff.org/content/2003/ 3218 [Assessed 6th of July, 2003]

15. Bradner CH, Ku L, Lindberg LD. Older, but not wiser: how men get information about AIDS and sexually transmitted diseases after high school. Family Planning Perspectives 2000; 32(1):33-8

16. Danielson R, Marcy S, Plunkett, A. et al. Reproductive health counseling for young men: what does it do?. Family Planning Perspectives 1990; 22:115-120

17. Aplasca MR, Siegel D, Mandel J et al. Results of model AIDS prevention program for high school students in Philippines. AIDS 1995; 9(1):S7-13

18. Leigh BC, Morrison DM, Trocki K, Temple MT. Sexual behavior of American adolescents: results from a U.S. national survey. Journal of Adolescent Health. 1994; 15(2):117-25

19. Mensch BS, Hewett C, Erulkar AS. The reporting of sensitive behavior by adolescents: a methodological experiment in Kenya. Demography 2003; 40(2):247-268

20. Dare OO, and Cleland JG. "Reliability and validity of survey Data on Sexual Behavior" Health Transition Review: AIDS impact and Prevention in the Developing World 
Demography. Social Science Perspectives 1994; 4 (Supplement):93-110

21. Fenton KA, Johnson AM, McManus S, and Erens B. "Measuring Sexual Behavior: Methodological Challenges in Survey Research". Sexually Transmitted Infections 2001; 77:84-92

22. Turner CF, Miller HG, and Rogers SM. "Survey Measurement of Sexual Behavior: Problems and Progress, In Researching Sexual Behavior: Methodological issues. J Bancroft (Eds), Bloomington: Indiana University Press. 1997; Pp 37-50

23. De Jarlais DC, Miliken CF, Turner H. et al. "Audio-Computer Interviewing to Measure Risk Behavior for HIV among Injecting Drug
Users: A Quasi Randomized Trial”. Lancet 1999; 353:1657-61

24. Fu H, Darroch JE, Henshaw SK, and Kolb E. "Measuring the Extent of Abortion Underreporting in the 1995 National Survey of Family Growth" Family Planning Perspectives 1998; 30:128-33

25. Hewett PC, Mensch BS, and Erulkar AS. Consistency in the reporting of sexual behavior by adolescent girls in Kenya: a comparison of interviewing method. Sexually Transmitted Infections 2004; 80(S2): ii43-8 